\title{
Analysis of the Development of Supply Chain Management as a Concept of Strategic Alliance Management
}

\author{
Luka Samaržija \\ Assistant professor \\ Faculty of Economics and Business \\ 51000, Rijeka \\ Croatia
}

\begin{abstract}
This paper reviews the origins and stages of development of the concept of supply chain management. In the first stage of the development process, the emphasis is placed on linking business processes within a company aimed at improving cost control and taking the efficiency of a business to a higher level. The possibilities of applying the concept are expanding in the following stages and the paper investigates the application of the concept in managing a network of independent organisations or strategic alliance network. Today, supply chain management is one of the key factors affecting the competitiveness of businesses having positive effects on customer satisfaction in terms of meeting their needs timely and effectively, reducing costs, reliable delivery service and improving quality of products and services.
\end{abstract}

Keywords: Supply Chain Management, Competitiveness, Competitive Advantage

\section{Introduction}

Information technology development in dynamic environments and consumer preferences that are changing fast in today's global market tend to weaken an independent company's competitive advantage strategies to compete against strategic alliances in supply chains. Business process optimization requires independent companies to focus exclusively on their core competencies and integrate their value chains by interacting with their partners in a supply chain, from unprocessed raw materials to delivery of finished products to the end user, in order to maximize their business process efficiency and effectiveness and gain a competitive advantage in the market. Integrated value chains allow for independent companies to provide opportunities for adding value through strategic alliances in supply chains in a synergistic interplay. Individual logistics flow management goals of an independent company are mapped back to the entire value chain process involving interrelated companies starting with acquisition of raw materials to delivery of finished products to the end user.

Supply chain management is becoming a modern concept of enterprise performance management through a new model of cooperative competitiveness. The future, which has already begun, involves supply chains that are increasingly competing with other supply chains rather than companies competing with other companies.

Formerly understood as a concept of managing vertically integrated structures, the term 'supply chain management' has recently expanded to managing independent companies as strategic alliances, or virtual integration of individual value chains of all the independent companies into a unique value adding management system.

\section{Development of the supply chain management Concept}

During transition to the new millennium, businesses faced growing pressure to become more flexible and adaptable to fast changes in consumer preferences. That period of intensified development of business logistics as a function of management was marked by the search for new methods allowing cost minimization and shorter inventory cycles, as well as techniques for predicting future production needs, which has been manifested in the concept of supply chain management. The first definitions of the term 'supply chain management' were focused on logistics management, followed up by lean supply chain, so the concept of supply chain management has expanded over time. Today, it is most often used to define the management of various forms of strategic alliances with the aim of managing information, materials and financial flows in creating added value for independent companies.

The extended concept of logistics management includes integrated value chain process management - from raw materials to the end consumer, regardless of relationships among the participants in the supply chain as a business system. In the period after 2000, changes in the business environment have become the most dynamic in history, influencing further development of the supply chain management concept. Among them, the most significant are as listed below (Ogden, 2006):

- Intensifying competition in the global market;

- Increase in numbers of strategic alliance between companies;

- Adapting business structures to processes across companies; 
- Growing importance of information technology in business management;

- Reducing number of suppliers;

- Abandoning mass production in favour of custom production;

- Promoting cooperation between manufacturers and their partners (suppliers and customers) when creating products, etc.

In line with these contextual changes, definitions of supply chain management have also changed over time. Initially viewed from a logistics aspect, supply chain management meant integration of different functions within an organization to improve the flow of goods from supplier to end user. The idea of supply chain management was developed on long-term relationships with suppliers and customers, and on continuous improvement in product quality and reduction of costs (Waters, D., 2003).

Over time, the meaning of supply chain management has become more important and has included collaboration with other companies, so Tan, et al. (1998) concluded that supply chain management was a function of management of a network of interrelated companies that collaborate to deliver a product or provide a service to the end customer by linking flows from raw materials to final delivery.

The Council of Supply Chain Management Professionals defines supply chain as a process of production and distribution of goods from a supplier's supplier to a customer's customer. Its structure is suitable for analysing horizontal and vertical relations within and across companies.

The idea of supply chain management came into focus of experts and scientists when it became clear that it was not enough to improve efficiency within a company, but that the entire supply chain needed to be more competitive (Jones, 1998). The concept of supply chain management has been explored from various perspectives, such as supply, warehousing and transportation management, operations management and marketing, as well as communication and relationship management. This led to defining supply chain as a network of facilities and distribution channels involved in acquisition of raw materials, transformation of these materials into intermediate and finished products, and distribution of finished products to customers. In general, a supply chain can be defined as an integrating function with responsibility for linking all business functions, practices, processes, and activities within a unique established flow of material, finances and information in a strategic alliance with the aim of improving business indicators of alliance members and the entire business system (Samaržija, 2014). The concept of supply chain management began to be applied more intensively when companies, seeking to gain competitive advantage and achieve more efficient value chain management, increasingly started to enter into strategic alliances to optimize value added processes by participating in joint product. The term 'alliance' is commonly used to depict collaborative behaviour in a temporary context. Alliance is an arrangement between companies working together to achieve a common goal, which an individual company alone could not achieve. The idea behind this business logic on establishing cooperation or starting a partnership between companies is to exploit logistics synergies enabling a company to create more added value than it could by acting alone. As a result of partnership, companies should be rewarded with extra profit generated on the account of a higher degree of specialization and better utilization of specific competencies. Following this logic, modern companies are increasingly striving to participate in the creation of a complete joint product through partnerships, interrelating their production competencies and logistics systems. Systematic strategic networking of companies with competitors, customers and / or suppliers aimed at creating additional value to products and services and gaining a competitive differential advantage in target market has resulted in a logistics concept of managing strategic alliances as business systems.

\section{From Enterprise to Business System}

Managing the supply chain as a business system in which participants are linked to each other through interconnected activities - a strategic alliance, is becoming key in achieving sustainable competitive advantage in an increasingly turbulent and competitive market, marked by a growing consumer dominance. The formation of strategic alliances has been seen as a response to intense changes in the business environment. Strategic cooperation implies implementation of supply chain management as a business management subsystem that manages all entities in the value-added chain.

A strategic alliance can be defined as a supply chain that includes all participants involved in a series of steps from the very beginning stage of sourcing the raw materials to the final delivery of the product or service to end users. A supply chain encompasses all activities, inside and outside a company, which are involved in creating added value to products and services for alliance members and end consumers. Supply chain management is an integrating and coordinating function that involves all activities of all the partners in the chain in a process of creating value for customers, which results in achieving the optimal conditions enabling companies participating in the supply chain, or alliance as a business system to accomplish their goals. Supply chain management drives coordination of resources and optimization of activities with the aim of gaining an advantage over the competition and indirectly enabling companies in the supply chain to maximize their business results. 
Zeng and Chen (2003) defined alliance as a broad term referring to partnership agreements in which partners explicitly agree to work together in the belief that they are more likely to succeed than by working alone. This form of organization is a strategic alliance in which companies are related to key suppliers and customers. Key suppliers ensure fast and efficient execution of operations within the system, thus making business processes more efficient (Samaržija, 2014). Companies can create new value through vertical or horizontal strategic alliances. According to Shiva (1997), competitive enterprises working together to develop new technology or penetrate new markets are horizontal alliances, whereas vertical alliances describe the collaboration between a company and its upstream and downstream partners in the supply chain. Value chain is a series of activities, which combined, define the supply chain in which independent companies collaborate with each other. In general, supply chain can be described as a network that links different entities, from customers to suppliers, through the production of goods and the provision of services in a way that allows efficient management of material, finances and information flows to meet business requirements (Zigiaris, 2000).

The objective of a supply chain is to maximize total value added. The value generated by a supply chain is the difference between what the final product is worth to customers and the costs incurred in the supply chain in meeting customer requirements. Determining how each participant is contributing to value creation and participating in the costs is an initial prerequisite for successful supply chain design and functioning, aimed at creating value added for customers and economic value added for the entire business system, or all members of the alliance.

Entities of different economic power operate within a supply chain. Nevertheless, they are all integrated by nature of supply chain operations. Weaknesses of one participant can affect the overall performance of the supply chain. A well-integrated supply chain requires coordination between all entities and intermediaries, which should include coordination of material and information flows between suppliers, manufacturers, and customers (Narasimhan and Carter, 1998). Supply chain management is an integrating and coordinating function that involves all resources and activities of all the participants in a business system with the aim of gaining an advantage over the competition and optimizing business results.

Supply chain design is a process that starts with setting goals of a partnership and defining criteria for joining an alliance of companies, which are ready to share information and trust each other to accomplish common goals. Supply chain design is the process by which the supply chain is structured in order to identify the right balance between internal and external participants in the transformation of inputs into outputs for consumers, defining integration factors to influence synergies between alliance members and to help boost customer satisfaction, resulting in enhanced competitiveness of the alliance and improved performance of companies participating in the supply chain.

Information sharing is a key determinant of supply chain partnership success, because in order to find common solutions to their common problems, supply chain participants must agree to share information about these problems (Carr and Pearson, 1999). Efficient cooperation in a supply chain leads to an increase in the competitiveness of the supply chain, and consequently the success of all participants and the entire supply chain as a business system.

When companies collaborate, they tend to adopt new technologies, conquer new markets, improve their business, and increase profitability. The cooperation strategy therefore allows companies to keep their costs low while improving the level of service to meet growing customer expectations. In general, the top three benefits of supply chain collaboration are: cost reduction, joint risk management, and increased power in negotiation (Omri, 2010).

The first major benefit of collaboration is cost reduction through shared resources and economies of scale. Forming supply chain-related alliances allow independent companies to significantly reduce their inventory and transportation costs through various forms of collaboration. This is the expected result of cooperative coordination of logistics flows of the partners in a supply chain. With joint orders, business can benefit from economies of scale, and significant savings can be done through joint investments in certain assets.

The second benefit of collaboration is improved risk management. In other words, a company that joined a supply chain, no longer has to deal alone with any internal or external disturbances it faces. Companies joining forces in an alliance are enabled to take a joint approach to managing risks making risk management more efficient.

Third and finally is the benefit of power. When there are several partners willing to work together, they are to create a system in which they are joined by forces and can benefit from an enhanced negotiating power. The case of partners joining forces to impose a price decrease to the suppliers could serve as an example. However, despite of the potential advantages, many collaborative supply chain forms fail to reap the benefits. It turns out that the success of a supply chain business system is not only related to good intentions of collaboration. There are a number of factors that can hinder the development and success of a supply chain partnership. Success of an alliance presupposes trust between partners, compromise, interdependence of partners, organizational compatibility in terms 
of goals, purposes, business philosophies, and corporate cultures, as well as a shared vision and key processes (Mentzer, et al., 2001). Problems tend to arise from interim rivalry or inconsistencies in companies' efforts to cooperate, including reluctance to share information, skills, and processes, as well as opportunistic behavior (Park and Ungson, 2001). Supporting and opposing forces can be seen as constants for cooperation in strategic partnerships, so supply chain management strategies should be focused around these as unavoidable entities in successful business management systems.

In addition to the factors mentioned above, which could cause a partnership to fail, even before it is formed, there is another kind of obstacle that seems particularly relevant to the success of a supply chain. This obstacle does not mean not contributing to value creation, but can be described as an attempt to seek an unfair share of the value created (Gilbert and Cvsa, 2003). Any acquisition of an unfair share of the value created could lead to a partner leaving a partnership.

In social networks such as supply chains, game theory is used as a tool to deal with these problems. In other words, one of the main contributions of the game theory is the development of models that allow all collaborating parties to agree on cost and / or benefit sharing in a way that each party would feel that acting as a coalition is worthwhile for its own sake (Anily and Haviv, 2007). Otherwise, decline of cooperation in a supply chain is likely to decrease competitiveness of the supply chain, and consequently business performance of the participants and the entire supply chain as a business system.

An integrated management system that integrates all of a supply chain flows increases competitiveness of the entire supply chain or business system linking together all the interrelated companies.

\section{Supply Chain Management as a Source of Competitive Advantage}

By designing a supply chain as a business system built on a foundation of equal participation of partners that have compatible goals, supply chain management allows companies to effectively manage the logistics flow of material, finances and information along value chain to supply customers with the right products and services at the right price at the right place and at the right time. At the same time, this leads to maximizing customer satisfaction in terms of their needs and expectations and gaining a competitive advantage or improving performance of participating companies and the entire supply chain as a system.

The concept of competitive advantage has been defined from different scientific points of view. Thus, Li et al. (2006) pointed out that competitive advantage is the capability of an organization to create and maintain a defensible position over its competitors, and Barney (2002) suggested that a company can gain a competitive advantage when its technology or market activities generate economic value in competition with other companies carrying out similar activities.

Previously it was widely believed that competitive advantage implies certain choice in terms of the market in which a company would compete, depending on market share in a clearly defined segment, through price-product ratio (Day, 1994). In a new global environment, successful businesses are those that are able to accurately predict market trends and respond quickly to changing customer needs (Stalk et al., 1992). The formation of strategic alliances and the implementation of supply chain management as a model for development of cooperative competitiveness is a response to challenges posed by today's market, characterized with too much product diversity and increasingly shorter deliver times. Modern companies are forced to find flexible ways to successfully meet the changing needs and expectations of customers, implementing logistics concepts of participatory management with the aim of achieving dynamic optimization of business performance by developing cooperative competitiveness.

Businesses today are focusing on optimizing their core activities to increase the speed of response to customer demand. In today's markets, characterized with customers with diversified demands and personalized products, supply chains need to respond to a constantly changing business environment. This obliges supply chain managers to strive for a better understanding of business flexibility and adaptability and the logistics concept of business management systems.

Most research to date has focused on manufacturing flexibility or ability at enterprise level. It is widely accepted, however, that competition is no longer between independent companies, but between supply chains. Lummus and Vokurka (1999) argued that successful organizations are those that manage to quickly untie all the nodes of the supply chain from suppliers' supplier to the customers' customer. The integration of suppliers, manufacturers and customers into an organised system, or logistics supply chain management from raw materials to the final consumer, in order to achieve flexibility and adaptability to customer requirements, has now become a prerequisite for modern business sustainability. A fundamental factor affecting supply chain management efficiency is the focus on time, flexibility, and speed of response allowing a supply chain to achieve success in today's increasingly dynamic global market (Stalk and Hout, 1990). Supply chain flexibility can be defined as a supply chain capability to respond to internal and external influences, whereas speed of response (adaptability) is the capability of a supply chain to respond quickly to changes in demand. 
A goal that is a secret to success is an organization's ability to match internal speed with external changes. Time inconsistency, competitive relationships and unsystematic sharing of information between independent companies in the process of adding value to products, from raw materials to the final consumer, are likely to prevent independent companies from fighting on an equal footing with strategic alliances in a well-established supply chain management system.

Supply chain management as an integrating and coordinating function that involves all of the value chain activities increases the speed of response of a supply chain, as one of the most important factors of competitiveness in today's dynamic market. Supply chain integration is the extent of interconnectedness of all the organization's activities, and across organizational boundaries with suppliers and customers (Stock et al., 2000), so it presupposes effective communication between all members of the supply chain. Supply chain managers are seeking to design agreed forms of integration and perform functions of management, which will enable the achievement of the speed of competitive responses and the required flexibility of the supply chain as a business system. The speed of response of a supply chain has become a source of competitive advantage. Organizations that have attained high response rates will be more able to accommodate demand variations and battle uncertainty in the business environment at lower costs on the account of shorter order cycle times (Randall et al., 2003).

Thatte (2007) found that the response time of a supply chain is positively related to competitive advantage, suggesting that higher response rates assure lower costs, contributing to gaining competitive advantage from different aspects. On the practical level, organizations that can respond quickly to customer requirements will be able to compete based on cost, quality, time to market, and reliability of delivery. It has been agreed, from different points of view, that the time, flexibility and speed of response can be sees as factors affecting competitiveness of modern business systems, which can be most effectively achieved through cooperation along the value chain and implementation of the logistics management concept. An optimally designed supply chain provides the maximum customer satisfaction and the highest business results of each participant in the supply chain, through realisation of activities which can contribute to increase in customer perceived value.

Supply chain management as a model for managing integrated value chains in well-established strategic alliances has become an indispensable concept of development of business competitiveness in today's turbulent business environment. This concept provides cooperative competitiveness unattainable by traditional business management models where individual companies act independently. Supply chain management has been defined to create economic value added as a result of organization synergy that occurs when specialized businesses logistically merge together to meet customers' diversified needs and ever-growing expectations. Innovative flexibility and speed of response, or time-based competition derived from efficient cooperation in the supply chain are elements of dynamic optimization of the performance of companies involved in the supply chain and competitiveness of the entire supply chain as a business system in a dynamic global market.

\section{Conclusion}

The paper provided a review of the concept of supply chain management as a key factor affecting competitiveness of strategic alliances. The implementation of this concept shows that economic value added creation occurs as a result of synergies achieved by companies by interrelating their business processes. Integrated strategic management brings benefits for independent companies in the form of a higher level of internal flexibility, but also for the entire strategic alliance, as well as adaptability to meet fast-growing customer needs. Taking into account the nature and dynamics of a company's external environment, it can be concluded that in the future supply chain management will have even greater importance and influence on the planning, design and management of strategic alliances.

\section{Literature:}

Zigiaris, S.: (2000) Supply Chain Management, Report produced for the EC funded project.

Ogden, J. A. (2006): Supply base reduction: an empirical study of critical success factors, Journal of Supply Chain Management, vol. 42, no. 4., p. 29.

Waters, D.: Logistics - An Introduction to Supply Chain Management, Palgrave Macmillan, New York, 2003.

Tan, K.C., et al., (1998): Supplychain management: supplier performance and firm performance, International Journal of Purchasing and Materials Management, 34 (3), 2-9.

Jones C., (1998): Moving beyond ERP: making the missing link. Logistics Focus, 6(7): 2 - 7.

Zeng, M. \& Chen, X., (2003): Achieving cooperation in multiparty alliances: a social dilemma approach to partnership management. Academy of Management Review, 28:587-605.

Shiva, R.S., (1997): Strategic alliances : building network relationships for mutual gain. New Dehli: Response Books.

Narasimhan, R. \& Carter, J., (1998): Linking business unit and material sourcing strategies.

Carr AS \& Person JN., (1999): Strategically managed buyers-seller relationships and performance outcomes. Journal of Operations Management, 17(5):497-519. 
Omri, E. A., (2010): Cooperation in supply chains : alliance formation and profit allocation among independent firms, Thesis, ECOLE CENTRALE DES ARTS ET MANUFACTURES «ECOLE CENTRALE PARIS $\gg$.

Mentzer, J. T., et al., (2001.): Defining Supply Chain Management, Journal of Business Logistics, 22(2), 1 - 25.

Park, S. \&Ungson, G., (2001): Inter- rm rivalry and managerial complexity: a conceptual framework of alliance failure, Organization Science, 12:37-53.

Gilbert, S. \&Cvsa, V., (2003): Strategic commitment to price to stimulate downstream inno-vation in a supply chain, European Journal of Operational Research, 150:617-639.

Anily, S. \&Haviv, M. (2007): The cost allocation problem for the rst order ineraction joint replenishment model, Operations research, 55: $292-302$.

Li, S., et al., (2006): The impact of supply chain management practices on competitive advantage and organizational performance, Omega, 34(2), 107-124. http://dx.doi.org/10.1016/j.omega.2004.08.002.

Barney, jay B. (2002): Gaining and Sustaining Competitive Advantage, $2^{\text {nd }}$ ed. Reading, Mass, Addison-Wesley.

Day, G. S., (1994): The Capabilities of Market-Driven Organizations, Journal of Marketing, 58(4), 37-52.

Stalk, G., Evans, P., Shulman, L. E., (1992): Competing on Capabilities: The New Rules of Corporate Strategy, Harvard Business Review, 70(2), 54-65.

Lummus, R. R. \&Vorkurka, R. J. (1999): Defining Supply Chain Management: A Historical Perspective and Practical Guidelines, Industrial Management \& Data Systems, 99 (1), $11-17$.

Samaržija, L.: (2014): Optimizacijadrvnihklasteraprimjenomkonceptamenadžmentaopskrbnoglanca, doktorskadisertacija, Ekonomskifakultet Rijeka

Stock, G.N., et al., (2000): Enterprise logistics and supply chain structure: the role of fit. Journal of Operations Management;18(5), 531-47.

Randall, T. R., et al ,(2003): Efficient versus Responsive Supply Chain Choice: An Empirical Examination of Influential Factors, Journal of Product Innovation Management, 20(6), 430-443.

Thatte, A.A., (2007): Competitive advantage of a Firm Through Supply Chain Responsiveness and Supply Chain Management Practices, Published PhD Dissertation, University of Toledo. 